Check for updates

Cite this: RSC Adv., 2019, 9, 6510

Received 6th December 2018

Accepted 15th February 2019

DOI: 10.1039/c8ra10053e

rsc.li/rsc-advances

\section{Observation of the generation of peroxynitrite in mouse liver after acetaminophen overdose with a boronate-based ratiometric fluorescence probe $\uparrow$}

\author{
Ying $\mathrm{Ma}^{a}{ }^{a}$ Haigang Tian, ${ }^{\mathrm{a}}$ Zhengyu $\mathrm{Jin}^{\mathrm{a}}{ }^{\mathrm{C}}$ Xiaoyong $\mathrm{Li}{ }^{\mathrm{b}}$ and Yiping $\mathrm{Li}$ (D) *a
}

A ratiometric fluorescent probe, $\mathrm{BTPB}$, for the selective monitoring of hepatic peroxynitrite $\left(\mathrm{ONOO}^{-}\right)$in situ after acetaminophen (APAP) overdose has been developed. Our study provided direct evidence for supporting the generation of $\mathrm{ONOO}^{-}$in APAP-induced liver injury. This new probe will be a useful tool for studying the roles of $\mathrm{ONOO}^{-}$in vivo.
Acetaminophen (APAP) is a safe and effective antipyretic/ analgesic drug when used at recommended doses, and is one of the most commonly used drugs in the US and throughout the West. ${ }^{1}$ However, APAP overdose can cause severe acute liver injury with the potential to progress to liver failure. It is responsible for almost 80000 emergency department visits in the US each year, ${ }^{2}$ as well as 26000 hospitalizations and nearly 500 deaths. $^{3}$ In fact, APAP hepatotoxicity is one of the most common etiologies of acute liver failure. ${ }^{4}$

Despite substantial progress in understanding the mechanism of APAP-induced liver injury during the last four decades, many details are still unknown. At therapeutic levels, about 50$70 \%$ of the administered APAP is glucuronidated, and $25-35 \%$ undergoes sulfation, while only $5-10 \%$ is converted to the reactive electrophilic intermediate $N$-acetyl-p-benzoquinone imine (NAPQI) by cytochrome P450 enzymes. ${ }^{5}$ NAPQI can be detoxified by reaction with the cysteine sulfhydryl group on glutathione (GSH). Once the administration of APAP overdose, NAPQI can deplete GSH stores, and bind to protein sulfhydryl groups, especially mitochondrial proteins, which triggers mitochondrial oxidant stress. The amplification of mitochondrial oxidative stress further leads to the opening of the mitochondrial membrane permeability transition (MPT) pore, then the rupture of the outer mitochondrial membrane. As a result, there is extensive release of proteins from the intermembrane space, including endonuclease $\mathrm{G}$ and apoptosis-inducing factor, both of which can translocate to the nucleus because of their nuclear localization sequences. This then results in DNA fragmentation and, finally, oncotic necrosis. ${ }^{6}$

${ }^{a}$ School of Pharmacy, Health Science Center, Xi'an Jiaotong University, Xi'an 710061, Shaanxi, China.E-mail: yipingli@mail.xjtu.edu.cn

${ }^{b}$ School of Science, Xi'an Jiaotong University, Xi'an 710061, Shaanxi, China. E-mail: lixy6658@mail.xjtu.edu.cn

$\dagger$ Electronic supplementary information (ESI) available: Experimental procedures, supplemental spectra, and the ${ }^{1} \mathrm{H}-,{ }^{13} \mathrm{C}-\mathrm{NMR}$, and MS spectra. See DOI: 10.1039/c8ra10053e
During resulting in MPT, it was recognized that the strong oxidant and nitrating peroxynitrite $\left(\mathrm{ONOO}^{-}\right)$, formed from superoxide $\left(\mathrm{O}_{2}{ }^{\cdot-}\right)$ and nitric oxide (NO), is being generated in hepatocytes and a critical mediator in the injury mechanism. The generation of $\mathrm{ONOO}^{-}$was only demonstrated by immunohistochemical staining for 3-nitrotyrosine protein adducts. ${ }^{7,8}$ The well-known nitration mechanism involves the initial oneelectron oxidation of tyrosine to yield tyrosyl radical followed by a diffusion-controlled reaction with nitrogen dioxide $\left({ }^{\circ} \mathrm{NO}_{2}\right)$ to yield 3-nitrotyrosine. ${ }^{9,10}$ However, in biological systems, ${ }^{\circ} \mathrm{NO}_{2}$ arises from a variety of sources, except most notably the decomposition of $\mathrm{ONOO}^{-}$, but the hemeperoxidase-dependent oxidation of nitrite, ${ }^{10,11}$ which is a $\mathrm{ONOO}^{-}$-independent mechanism. Actually, protein 3-nitrotyrosine, which was initially conceived as a specific footprint of $\mathrm{ONOO}^{-}$, typically represents a fairly stable end product that is generated by the action of NOderived oxidants. ${ }^{12}$ It seems insufficient for the generation of $\mathrm{ONOO}^{-}$after the administration of APAP overdose only according to the observation of the formation of protein 3nitrotyrosine. Therefore, there is an urgent need to provide the direct evidence for supporting the generation of $\mathrm{ONOO}^{-}$after APAP overdose.

The lifetime of $\mathrm{ONOO}^{-}$in biological systems is limited to only a few milliseconds, which makes it impossible to quantitate $\mathrm{ONOO}^{-}$in processed cell or tissue samples directly. ${ }^{13}$ Fluorescence based techniques are advantageous for detection of $\mathrm{ONOO}^{-}$. In accordance with the multiplicity of $\mathrm{ONOO}^{-}$ biochemistry, ${ }^{14}$ the trifluorocarbonyl (HKGreen $\left.1-3\right)^{15-17}$ and phenyl boronic esters (CBA) ${ }^{18}$ based fluorescent probes, which can directly detect $\mathrm{OONO}^{-}$, have been reported, mainly for in vitro applications. However, these probes are not suitable for biological studies in vivo because of their high molecular weight, bearing easily metabolized lactone group, such as HKGreen 1-3, or a low response signal, such as CBA. Chemiluminescence (CL) probes ${ }^{19,20}$ can distinguish $\mathrm{ONOO}^{-}$from a variety of other ROS owing to the radicals from the 
decomposition of $\mathrm{ONOO}^{-}$, such as $\mathrm{ONOOH},{ }^{\circ} \mathrm{OH}$ and $\mathrm{O}_{2}{ }^{\cdot-}$, not directly to the reaction with $\mathrm{ONOO}^{-}$. Additionally, CL probes were not used to detect $\mathrm{OONO}^{-}$in vivo.

In this regard, to provide direct and strong evidence for the formation of $\mathrm{OONO}^{-}$in liver after APAP overdose, we developed a novel and low background phenyl boronic acid-containing fluorogenic probe for sensitive and selective detecting of $\mathrm{OONO}^{-}$. This probe was introduced into the mice administrated APAP overdose by heart perfusion to monitor in situ the formation of $\mathrm{OONO}^{-}$in liver.

The new fluorescent probe was designed by the direct conjugation of an boronic acid reaction group with a (phenyl-2yl)benzothiazol scaffold, serving as a fluorophore. Phenyl boronic acid group was selected because the group can react with OONO $^{-}$directly, rapidly and stoichiometrically, ${ }^{21}$ which is more suitable to detect $\mathrm{OONO}^{-}$than other groups that react with those secondary radicals derived from $\mathrm{OONO}^{-}$, including $\mathrm{HONOO}, \mathrm{ONOOCO}_{2}{ }^{-}$, or metal-OONO${ }^{-}$complexes. Moreover, phenyl boronic acid group was recently reported to be highly reactive to $\mathrm{OONO}^{-}$nearly a million times faster than $\mathrm{H}_{2} \mathrm{O}_{2}$ and two hundred times faster than $\mathrm{ClO}^{-}{ }^{.22,23}$ The (phenyl-2-yl) benzothiazol scaffold was selected because the probe designed reacts with $\mathrm{OONO}^{-}$to yield corresponding hydroxyl derivatives 2-(benzothiazol-2-yl)phenol, which possesses the excellent photophysical properties, such as high photostabilities and high fluorescence quantum yields, of members of this family. ${ }^{24,25}$ The boronic acid group is converted to the hydroxyl by the reaction with $\mathrm{OONO}^{-}$, with the conversions offering ratiometric responses because 2-(benzothiazol-2-yl) phenylboronic acid (BTPB) and 2-(benzothiazol-2-yl) phenol (BTP) fluoresce at different wavelengths, which makes this probe sensitive. More importantly, benzothiazol group is metabolically stable and a usual drug fragments, ${ }^{26,27}$ and this probe has a low molecular weight and appropriate water solubility, which makes this probe suitable to use in vivo. The design rationale is depicted in Fig. 1, and illustrated as follows.

Probe BTPB was prepared using the one-step reaction shown in ESI. $\dagger^{28}$ 2-(Benzothiazol-2-yl) phenol, BTP, the expected product resulting from reaction of BTPB with $\mathrm{ONOO}^{-}$, was also prepared utilizing a previously described method.$^{29}$ The structures of BTPB and BTP were confirmed by ${ }^{1} \mathrm{H}$ NMR, ${ }^{13} \mathrm{C}$ NMR, and HRMS spectra (Fig. S1-S6†), which match those of literatures. ${ }^{28,29}$

Firstly, the spectroscopic response of BTPB to $\mathrm{ONOO}^{-}$was investigated in an abiotic system. We examined the spectroscopic properties of BTPB $(1.0 \mu \mathrm{M})$ towards $\mathrm{ONOO}^{-}$(1 equiv.) in $100.0 \mathrm{mM}$ PBS buffer with $1.0 \mathrm{mM}$ cetyltrimethylammonium bromide (CTAB) at $\mathrm{pH} 7.4$ at $25.0 \pm 0.1{ }^{\circ} \mathrm{C} .50 \mu \mathrm{L}$ of BTPB $(1.0 \mathrm{mM})$ was added to $\mathrm{ONOO}^{-}$(1.0 equiv.), then vigorously stirred for 30 seconds. After dilution to $1.0 \mu \mathrm{M}$ with $100.0 \mathrm{mM}$ PBS buffer 1.0 mM CTAB, the mixture was vigorously stirred for $1 \mathrm{~min}$ before measurement. The absorption and fluorescence spectra of BTPB before and after reaction with $\mathrm{ONOO}^{-}$are shown in Fig. 2. As is seen, BTPB shows a major UV-absorption centered at $296 \mathrm{~nm}$, but its reaction with $\mathrm{ONOO}^{-}$produces two absorption peak at $290 \mathrm{~nm}$ and $338 \mathrm{~nm}$. Moreover, BTPB itself displays a low fluorescence with the maximum emission peak at $372 \mathrm{~nm}$, whereas the reaction with $\mathrm{ONOO}^{-}$leads to a fluorescence enhancement with the maximum emission peak at $462 \mathrm{~nm}$.

The fluorescence response of BTPB to varied concentrations of $\mathrm{ONOO}^{-}(0-1.0 \mu \mathrm{M})$ was examined. When the emission wavelength was set to $372 \mathrm{~nm}$, upon addition of $\mathrm{ONOO}^{-}$, the

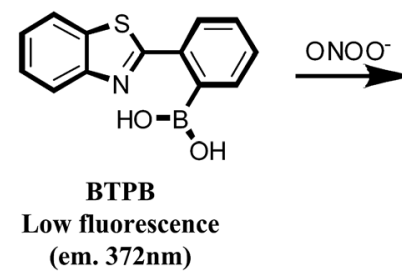

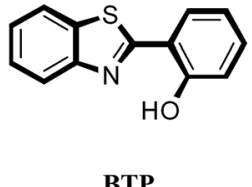

low fluorescence

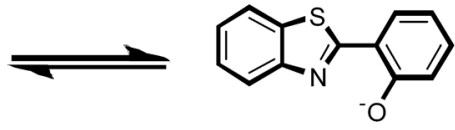

phenolate anion of BTP high fluorescence (em. 462nm)

Fig. 1 Structure of BTPB and detection of peroxynitrite by oxidation of BTPB.

(a)

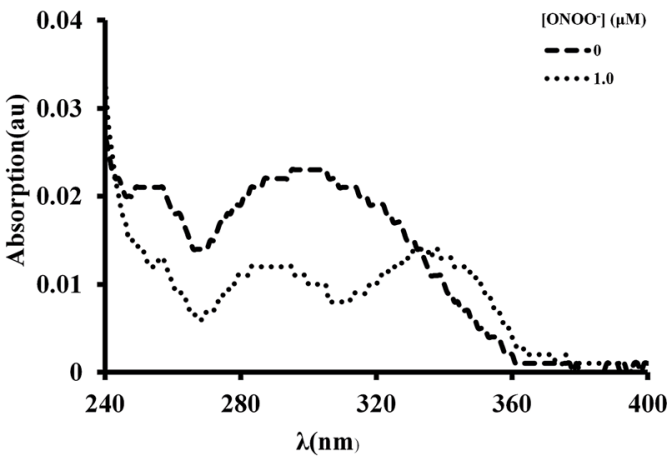

(b)

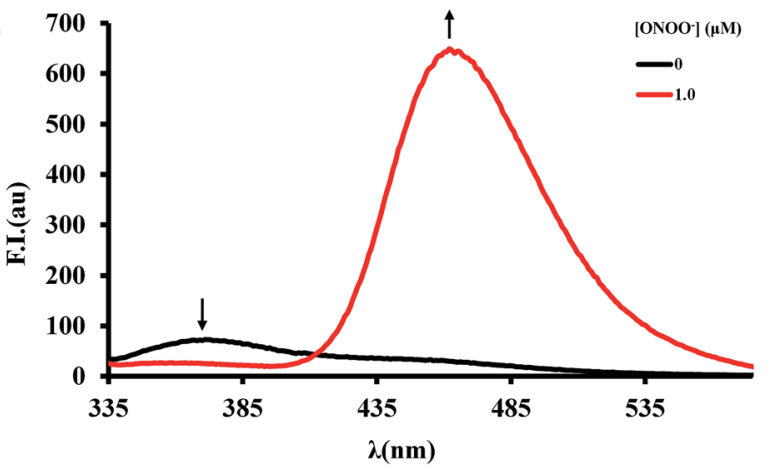

Fig. 2 Absorption spectra (a) and fluorescence spectra (b) of BTPB $(1.0 \mu \mathrm{m})$ before and after reaction with ONOO $\mathrm{ON}^{-}(1.0 \mu \mathrm{m})$. Spectra were obtained in $100.0 \mathrm{~mm}$ phosphate buffer $(\mathrm{pH} 7.4)$ with $1.0 \mathrm{~mm}$ cetyltrimethylammonium bromide (CTAB) under vigorous stirring for 1 min after incubation of the probe with $\mathrm{ONOO}^{-}$for 30 seconds at $25.0^{\circ} \mathrm{C}, \lambda_{\mathrm{ex}}=296 \mathrm{~nm}$. 
main excitation peak of BTPB at $296 \mathrm{~nm}$ decreases with a concurrent increase in excitation peaks at $296 \mathrm{~nm}, 332 \mathrm{~nm}$ and $386 \mathrm{~nm}$ when the emission wavelength was $462 \mathrm{~nm}$ (Fig. 3a and $b$ ). Thus, the ratiometric feature in the spectra was obtained at an excitation wavelength of $296 \mathrm{~nm}$.

As expected, in the absence of $\mathrm{ONOO}^{-}$, BTPB $(1.0 \mu \mathrm{M})$ in 100.0 mM PBS buffer with 1.0 mM CTAB at $\mathrm{pH} 7.4$ showed a very poor fluorescence at $372 \mathrm{~nm}\left(\phi_{\mathrm{F}}=0.05\right)$; upon addition of ONOO $^{-}(1.0 \mu \mathrm{M})$, a dramatic fluorescence enhancement was observed immediately at $462 \mathrm{~nm}\left(\phi_{\mathrm{F}}=0.33\right)$. The ratio of emission intensities $\left(F_{462} / F_{372}\right)$ upon excitation at $296 \mathrm{~nm}$ varies from 0.41 in the absence of $\mathrm{ONOO}^{-}$to 26.45 after reaction with $\mathrm{ONOO}^{-}$, a ca. 65-fold emission ratio change (Fig. 3c), which is more than the response signal of CBA. ${ }^{18}$ As shown in Fig. 3d, The ratio of emission intensities $\left(F_{462} / F_{372}\right)$ exhibits a good linear relationship in the concentration range of $0-1.0 \mu \mathrm{M}$ $\mathrm{ONOO}^{-}$with an equation of $F=27.27 \times\left[\mathrm{ONOO}^{-}\right](\mu \mathrm{M})+0.41$ $\left(R^{2}=0.988\right)$, where $F$ represents the ratio of fluorescence intensity of the reaction solution $\left(F_{462} / F_{372}\right)$. The detection limit was calculated to be $12.3 \mathrm{nM} \mathrm{ONOO}^{-}$. These results revealed that BTPB could potentially test $\mathrm{ONOO}^{-}$in abiotic systems, which is similar with physiological conditions, both qualitatively and quantitatively.

It is known that CTAB is a cationic surfactant and forms spherical micelles within the concentration range $0.9-100 \mathrm{mM}$ in water. Both BTPB and BTP are low soluble in water; to apply them efficiently in an aqueous environment, CTAB was introduced into the aqueous phase. Thus BTPB molecules could be encapsulated in micelles, which makes more intense emission of BTPB in CTAB-added PBS than that in PBS without CTAB (Fig. S7†). The formation of micelles was also confirmed by means of scanning electron microscopy (Fig. S8†).

The selectivity of BTPB $(1.0 \mu \mathrm{M})$ toward $\mathrm{ONOO}^{-}$was determined by measuring fluorescence changes that take place in the presence of various ROS and RNS including superoxide $\left(\mathrm{O}_{2}{ }^{-}\right)$, hypochlorite $\left(\mathrm{ClO}^{-}\right)$, hydroxyl radicals $\left({ }^{\circ} \mathrm{OH}\right)$, hydrogen peroxide $\left(\mathrm{H}_{2} \mathrm{O}_{2}\right)$, single oxygen $\left({ }^{1} \mathrm{O}_{2}\right)$, tert-butoxyl radical $\left({ }^{\circ} \mathrm{O}^{t} \mathrm{Bu}\right)$, nitrite $\left(\mathrm{NO}_{2}{ }^{-}\right)$and nitric oxide (NO) in phosphate buffer $(100 \mathrm{mM}, \mathrm{pH}$ 7.4, $1.0 \mathrm{mM} \mathrm{CTAB}$ ) at $25{ }^{\circ} \mathrm{C}$. As shown in Fig. 4, only $\mathrm{ONOO}^{-}$ promotes a dramatic enhancement in fluorescence intensity at $462 \mathrm{~nm}\left(F_{462} / F_{372}=26.5\right)$. In contrast, no changes in emission intensities occur when the probe was incubated with $\mathrm{O}_{2}{ }^{\cdot-}$, $\mathrm{H}_{2} \mathrm{O}_{2},{ }^{\circ} \mathrm{OH},{ }^{1} \mathrm{O}_{2},{ }^{\circ} \mathrm{O}^{t} \mathrm{Bu}, \mathrm{NO}_{2}{ }^{-}$and NO. $\mathrm{ClO}^{-}$induces a small fluorescence response $\left(F_{462} / F_{372}=1.2\right)$. Taken together, these results established that $\mathrm{BTPB}$ is sensitive enough and also considerably selective toward $\mathrm{ONOO}^{-}$over other ROS or RNS under the conditions of low concentration $(1.0 \mu \mathrm{M})$ and short reaction time $(1.0 \mathrm{~min})$. The observations also corroborate the previous finding that boronate-containing small molecules react with $\mathrm{ONOO}^{-}$much faster than with $\mathrm{H}_{2} \mathrm{O}_{2}$ or $\mathrm{ClO}^{-} .^{22,23}$

Our approach to develop a $\mathrm{ONOO}^{-}$specific probe relies on the use of oxidation of phenyl boronic acid group of BTPB to hydroxyl group of BTP. Subsequently, to confirm this reaction, the process taking place between $\mathrm{BTPB}$ and $\mathrm{ONOO}^{-}$was
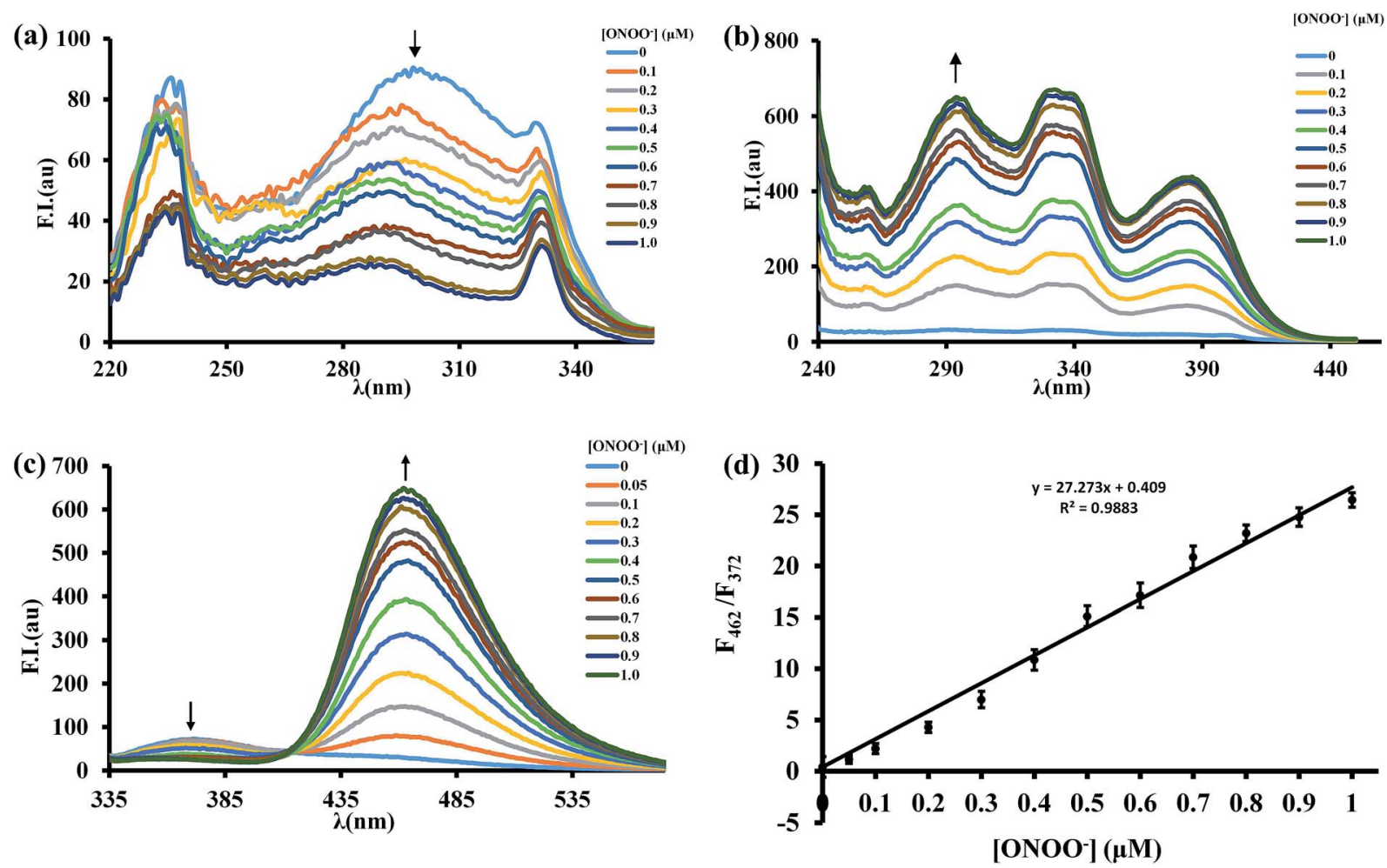

Fig. 3 (a) Fluorescence excitation spectra of BTPB $(1.0 \mu \mathrm{m})$ to $O \mathrm{ONO}^{-}\left(0-1\right.$ equiv.), $\lambda_{\mathrm{em}}=372 \mathrm{~nm}$. (b) Fluorescence excitation spectra of BTPB $(1.0 \mu \mathrm{m})$ to $\mathrm{OONO}^{-}\left(0-1\right.$ equiv.), $\lambda_{\mathrm{em}}=462 \mathrm{~nm}$. (c) Fluorescence emission spectra of BTPB $(1.0 \mu \mathrm{m})$ to $\mathrm{OONO}^{-}\left(0-1 \mathrm{equiv}\right.$ ) $\lambda_{\mathrm{ex}}=296 \mathrm{~nm}$. (d) Linear relationship of emission intensity ratio $\left(F_{462} / F_{372}\right)$ to $\mathrm{OONO}^{-}(0-1.0 \mu \mathrm{m})$. All spectra were obtained in $100.0 \mathrm{~mm}$ phosphate buffer $(\mathrm{pH} 7.4)$ with $1.0 \mathrm{~mm}$ cetyltrimethylammonium bromide (CTAB) under vigorous stirring for $1 \mathrm{~min}$ after incubation of the probe with $\mathrm{ONOO}^{-}$for 30 seconds at $25.0{ }^{\circ} \mathrm{C}$. 

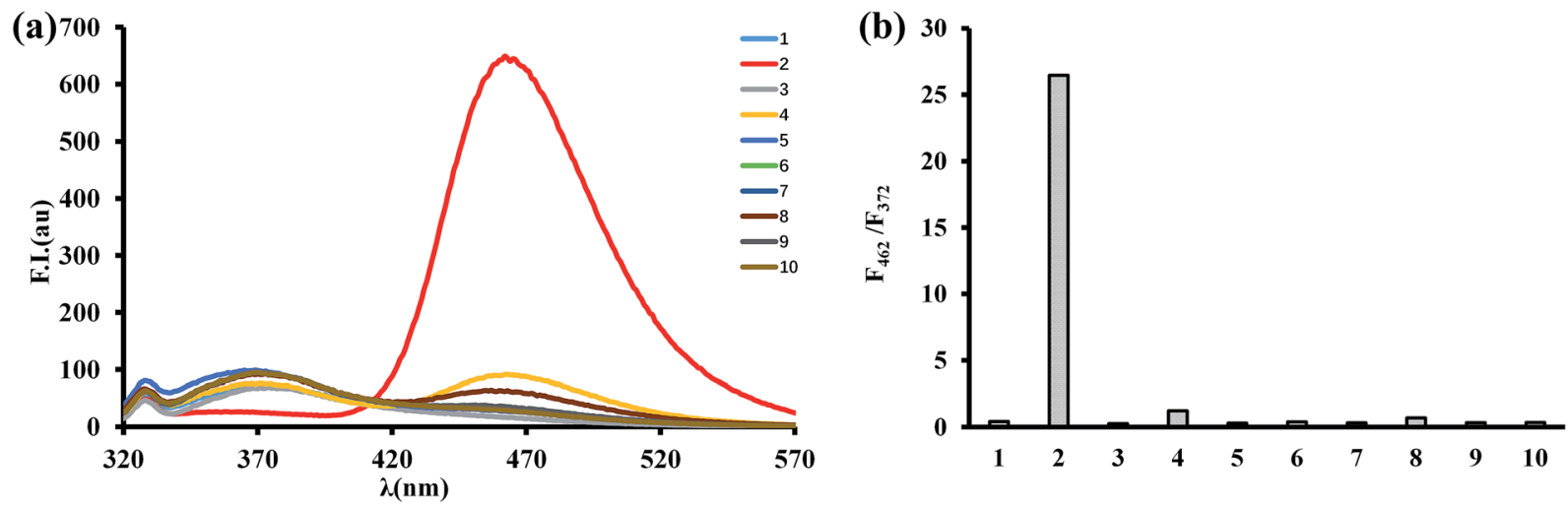

Fig. 4 (a) Fluorescence emission spectra of BTPB $(1.0 \mu \mathrm{m})$ to various ROS and RNS (1 equiv. ONOO- and 10 equiv. for other ROS and RNS). (1) Blank; (2) $\mathrm{ONOO}^{-}$; (3) ${ }^{\circ} \mathrm{OH}$; (4) $\mathrm{ClO}^{-}$; (5) $\mathrm{H}_{2} \mathrm{O}_{2}$; (6) $\mathrm{NO}_{2}^{-}$; (7) $\mathrm{NO}$; (8) $\mathrm{O}_{2}{ }^{--}$; (9) ${ }^{1} \mathrm{O}_{2}$; (10) ${ }^{\circ} \mathrm{O}^{t} \mathrm{Bu}$. (b) Emission intensity ratio $\left(F_{462} / F_{372}\right.$ ) of various $\mathrm{ROS}$ and RNS.

monitored by using HPLC. HPLC analysis of the mixture generated from the reaction of $\mathrm{ONOO}^{-}$with BTPB showed that in the presence of various concentrations of $\mathrm{ONOO}^{-}$, the intensity of the peak of BTPB (eluted at $2.0 \mathrm{~min}$ ) gradually decreased, in the meanwhile that of the peak of oxidation products BTP eluted at $5.5 \mathrm{~min}$ emerged and gradually increased (Fig. S9†). The results confirmed that the fluorescent product was indeed BTP, resulting from the $\mathrm{ONOO}^{-}$induced oxidation reaction of ВТРВ. The ratiometric fluorescence mechanism is concerned with internal charge transfer (ICT). The boron atom in boronic acid group is $\mathrm{sp}^{2}$ hybridized and possesses fiercely electron-withdrawing character due to the availability of its vacant $p$ orbitals, forming the ICT state with benzothiazol moity as the electron-donating group. After the reaction with $\mathrm{ONOO}^{-}$, the boronic acid group is converted to the electron-donating hydroxyl, which interferes internal charge transfer of BTPB molecule and results in fluorescent emission enhancement. The red shifts in emission maxima could be attributed to the lower-energy emission of the phenolate anion of BTP in PBS at pH 7.4, which matches the peak emission of the deprotonated phenolate anion of benzothiazol derivative in aqueous solution..$^{30,31}$

MTT assays (Fig. S10 $\dagger$ ) revealed that BTPB of concentrations below $40 \mu \mathrm{M}$ does not exhibit obvious cytotoxicity living HepG2 cells. Finally, encouraged by the above promising results, especially fast response rate (within 30 seconds), excellent sensitivity (detection limit $=12.3 \mathrm{nM}$ ) and high selectivity, BTPB was employed for confocal imaging of $\mathrm{ONOO}^{-}$in the liver tissue sample. $\mathrm{ONOO}^{-}$formation has long been implicated in APAP-induced liver injury on the basis of indirect detection, i.e., immunostaining of protein nitration, which, however, cannot be used as unique evidence for $\mathrm{ONOO}^{-}$formation. To address
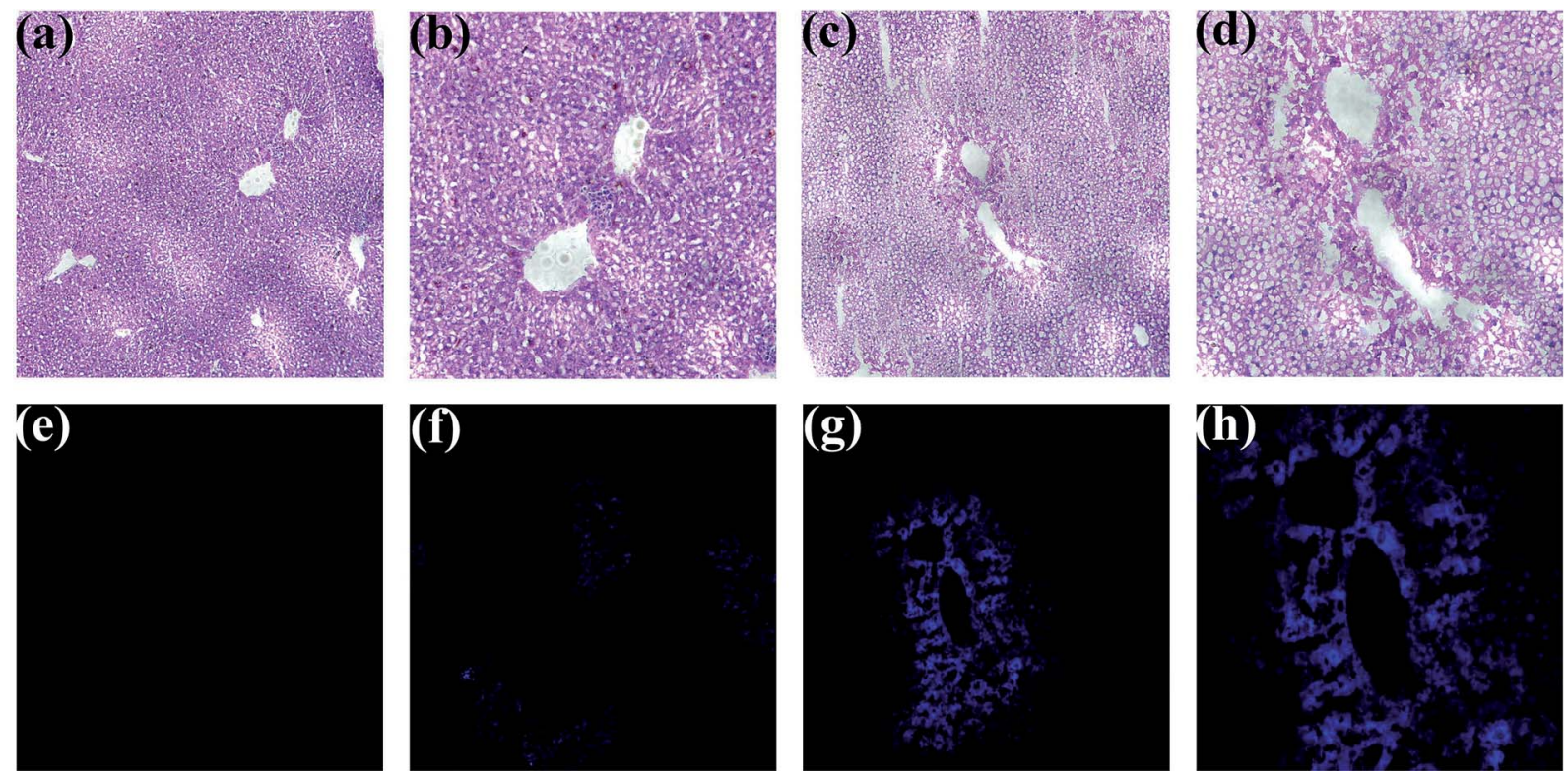

Fig. 5 Hematoxylin and eosin staining of liver sections for hepatic necrosis (a-d) and confocal microscopic fluorescence images of liver sections for detecting of ONOO ${ }^{-}$generation via BTPB (e-h) in controls and $6 \mathrm{~h}$ after $400 \mathrm{mg} \mathrm{kg}^{-1}$ APAP. (a) Control, $\times 100$. (b) Control, $\times 200$. (c) $6 \mathrm{~h}$ after $400 \mathrm{mg} \mathrm{kg}^{-1}$ APAP, $\times 100$. (d) $6 \mathrm{~h}$ after $400 \mathrm{mg} \mathrm{kg}^{-1}$ APAP, $\times 200$. (e) Control, $\times 100$. (f) $6 \mathrm{~h}$ after $400 \mathrm{mg} \mathrm{kg}^{-1} \mathrm{APAP}, \times 100$. (g) $6 \mathrm{~h} \mathrm{after} 400 \mathrm{mg}$ $\mathrm{kg}^{-1}$ APAP, $\times 200$. (h) $6 \mathrm{~h}$ after $400 \mathrm{mg} \mathrm{kg}^{-1}$ APAP, $\times 400$. 
this question, the mice administrated APAP overdose (400 $\mathrm{mg} \mathrm{kg}^{-1}$ ) were employed to monitor $\mathrm{ONOO}^{-}$formation in situ. Six hours after administrated APAP overdose, living heart tissues were perfused with BTPB $(1.0 \mu \mathrm{M})$ in saline for $3 \mathrm{~min}$ under anesthesia. Mouse livers were then excised and cryosectioned at $10 \mu \mathrm{m}$ intervals for confocal imaging and hematoxylin and eosin (HE) staining. The mice without APAP administration were perfused with BTPB as the control.

As shown in Fig. 5, HE staining of liver sections indicate the substantial centrilobular necrosis 6 hours after APAP administration, but no necrosis is observed in the control group without APAP administration, suggesting that APAP overdose induces liver injury, which is consistent with those studies. ${ }^{32,33}$ Then liver sections were monitored using a confocal microscope over the wavelength range of 417-477 $\mathrm{nm}$ with an excitation wavelength at $408 \mathrm{~nm}$. Without APAP administration no fluorescence in the liver sections was observed, while strong blue fluorescence in the centrilobular regions was imaged after treatment with overdose APAP, which correlated well with the areas of necrosis. This result indicates the generation of $\mathrm{ONOO}^{-}$during APAP-induced liver injury, which is the first direct evidence provided by our study. Also, these observations suggest that BTPB has satisfactory cell permeability and is wellretained during histological sample preparation and sensitive enough to visualize endogenous $\mathrm{ONOO}^{-}$in live tissues.

\section{Conclusions}

In summary, we present herein a ratiometric fluorescent probe for the highly sensitive and selective detection and hepatic imaging of $\mathrm{ONOO}^{-}$after APAP overdose. This probe was designed based on a $\mathrm{ONOO}^{-}$specific reaction with the boronic acid group. Our study provided the direct evidence for supporting the generation of $\mathrm{ONOO}^{-}$in APAP-induced liver injury. We believe that the probe with excellent spectroscopic properties will find its applications in understanding the actions of $\mathrm{ONOO}^{-}$in vivo.

\section{Conflicts of interest}

The authors declare no conflicts of interest.

\section{Acknowledgements}

We acknowledge the National Natural Science Foundation of China (Grant No. 81272448).

\section{Notes and references}

1 D. W. Kaufman, J. P. Kelly, L. Rosenberg, T. E. Anderson and

A. A. Mitchell, J. Am. Med. Assoc., 2002, 287, 337-344.

2 D. S. Budnitz, M. C. Lovegrove and A. E. Crosby, Am. J. Prev. Med., 2011, 40, 585-592.

3 P. Nourjah, S. R. Ahmad, C. Karwoski and M. Willy, Pharmacoepidemiol. Drug Saf., 2006, 15, 398-405.

4 W. M. Lee and S. Respir, Crit. Care Med., 2012, 33, 36-45.
5 M. R. McGill and H. Jaeschke, Pharm. Res., 2013, 30, 21742187.

6 H. Jaeschke, M. R. McGill and A. Ramachandran, Drug Metab. Rev., 2012, 44, 88-106.

7 J. A. Hinson, S. L. Pike, N. R. Pumford and P. R. Mayeux, Chem. Res. Toxicol., 1998, 11, 604-607.

8 T. R. Knight, A. Kurtz, M. L. Bajt, J. A. Hinson and H. Jaeschke, Toxicol. Sci., 2001, 62, 212-220.

9 S. Bartesaghi, G. Ferrer-Sueta, G. Peluffo, V. Valez, H. Zhang, B. Kalyanaraman and R. Radi, Amino Acids, 2007, 32, 501515.

10 R. Radi, Proc. Natl. Acad. Sci. U. S. A., 2004, 101, 4003-4008. 11 R. Radi, Acc. Chem. Res., 2013, 46, 550-559.

12 C. Batthyány, S. Bartesaghi, M. Mastrogiovanni, A. Lima, V. Demicheli and R. Radi, Antioxid. Redox Signaling, 2017, 26, 313-328.

13 R. Radi, J. Biol. Chem., 2013, 288, 26464-26472.

14 Q. Zhang, N. Zhang, Y. T. Long, X. Qian and Y. Yang, Bioconjugate Chem., 2016, 27, 341-353.

15 D. Yang, H. L. Wang, Z. N. Sun, N. W. Chung and J. G. Shen, J. Am. Chem. Soc., 2006, 128, 6004-6005.

16 Z. N. Sun, H. L. Wang, F. Q. Liu, P. K. H. Tam and D. Yang, Org. Lett., 2009, 11, 1887-1890.

17 T. Peng and D. Yang, Org. Lett., 2010, 12, 4932-4935.

18 J. Zielonka, A. Sikora, J. Joseph and B. Kalyanaraman, J. Biol. Chem., 2010, 285, 14210-14216.

19 W. Zhou, Y. Cao, D. Sui and C. Lu, Anal. Chem., 2016, 88, 2659-2665.

20 Z. Wang, X. Teng and C. Lu, Anal. Chem., 2015, 87, 34123418.

21 A. Sikora, J. Zielonka, M. Lopez, A. Dybala-Defratyka, J. Joseph, A. Marcinek and B. Kalyanaraman, Chem. Res. Toxicol., 2011, 24, 687-697.

22 A. Sikora, J. Zielonka, M. Lopez, J. Joseph and B. Kalyanaraman, Free Radical Biol. Med., 2009, 47, 14011407.

23 J. Zielonka, A. Sikora, M. Hardy, J. Joseph, B. P. Dranka and B. Kalyanaraman, Chem. Res. Toxicol., 2012, 25, 1793-1799.

24 R. Hu, J. Feng, D. Hu, S. Wang, S. Li, Y. Li and G. Yang, Angew. Chem., Int. Ed., 2010, 49, 4915-4918.

25 H. W. Chen, Y. Xing and Y. Pang, Org. Lett., 2011, 13, 13621365.

26 P. C. Sharma, A. Sinhmar, A. Sharma, H. Rajak and D. P. Pathak, J. Enzyme Inhib. Med. Chem., 2013, 28, 240-266.

27 R. D. Taylor, M. MacCoss and A. D. Lawson, J. Med. Chem., 2014, 57, 5845-5859.

28 A. B. Draganov, K. Wang, J. Holmes, K. Damera, D. Wang, C. Dai and B. Wang, Chem. Commun., 2015, 51, 15180-15183.

29 M. A. Chari, D. Shobha and T. Sasaki, Tetrahedron Lett., 2011, 52, 5575-5580.

30 M. M. Henary and C. J. Fahrni, J. Phys. Chem. A, 2002, 106, 5210-5220.

31 J. E. Kwon and S. Y. Park, Adv. Mater., 2011, 23, 3615-3642. 32 P. James, L. A. MacMillan-Crow and J. A. Hinson, J. Pharmacol. Exp. Ther., 2012, 340, 134-142.

33 C. Saito, C. Zwingmann and H. Jaeschke, Hepatology, 2010, 51, 246-254. 